\title{
Knowledge, attitude and practices towards e-learning: A feasibility study among first MBBS students of Government Medical College from hilly region of India
}

\author{
Susheela Rana', Onjal K Taywade ${ }^{2}$, Bandita Medhi' ${ }^{3}$ Monali Hiwarkar ${ }^{4}$ \\ ${ }^{1}$ Professor and Head, ${ }^{4}$ Associate Professor, Department of Anatomy, Shri Lal Bahadur Shastri Government Medical \\ College and Hospital, Ner Chowk, Mandi, Himachal Pradesh, India, ${ }^{2}$ Assistant Professor, Department of Biochemistry, \\ All India Institute of Medical Sciences, Bilaspur, Himachal Pradesh, India, ${ }^{3}$ Associate Professor, Department of \\ Anatomy, Shri Aurobindo Institute of Medical Sciences, Indore, Madhya Pradesh, India
}

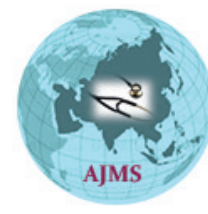

A B S TR A C T

Background: Nationwide lockdown tremendously affected academic and educational activities of medical students during the COVID-19 pandemic. The medical students like all other faculties resorted to the e-learning modalities. This has helped the first MBBS students to continue learning during this period of lockdown. Hence studies about perception of medical students towards e-learning are relevant. Aims and Objectives: To assess the first MBBS student's perception about e-learning and online classes. To evaluate feasibility of utilizing e-learning by assessing the acceptability, knowledge, attitude, skills and habits of first MBBS students. Materials and Methods: A questionnaire of 25 questions on various aspects of e-learning was administered to the first MBBS students at Government Medical College, Himachal Pradesh through google form $(n=100)$. They were asked to mark appropriate responses and the data was analysed to get the percentage and proportion on various aspects of e-learning. Results: The first MBBS students widely used e-learning resources to learn anatomy, physiology as well as biochemistry during COVID 19 pandemic. E-learning has made a positive impact on overall learning of first-year subjects, especially anatomy. The responses did not have any association with gender $(p>0.05)$. Conclusion: Distance learning can compensate for conventional teaching during pandemic, but cannot fully replace the traditional teaching in the medical institutes.

Key words: E-learning; COVID-19 pandemic; Medical education; MBBS first year students

\section{Access this article online}

Website:

http://nepjol.info/index.php/AJMS DOI: $10.3126 /$ ajms.v12i9.38075

E-ISSN: 2091-0576

P-ISSN: 2467-9100

Copyright (c) 2021 Asian Journal of Medical Sciences

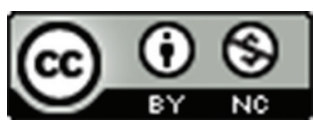

This work is licensed under a Creative Commons Attribution-NonCommercial 4.0 International License.

\section{INTRODUCTION}

In December 2019, novel coronavirus SARS-CoV-2 emerged in Wuhan, China which later spread across the world. The World Health Organization on March 11, 2020 declared COVID19 as a pandemic that is causing the disruption of human life even today when this article was written. ${ }^{1}$ To stop the spread of this virus, countries had to announce nationwide lockdown and even the education institutes were closed down. The medical students were not able to attend their regular classes during this pandemic owing to the lockdown measures imposed to control the spread of the virus. Students struggled to manage their day-to-day activities and their academic activities were restrained to be online learning only. Medical education itself is challenging, starting with cadaveric dissection, involving clinical postings and dealing with patients. ${ }^{2}$ Medical education was badly affected till the students and teachers adjusted to the new norms of e-learning.

With rapid advancement in technology, online education has reached students in India. University Grants Commission 
began to actively support online education models since 2018, allowing qualified institutions to offer more courses and certificate programmes online. Online mode of education got real momentum when the COVID-19 pandemic restricted student gathering for classroom or academic activities. The Ministry of Human Resource Development launched the 'Bharat Padhe Online' i.e. 'India Study Online' campaign in India to bring out ideas for improving the online education system. The ministry also has formally launched the 'Swayam portal' (https:// swayam.gov.in) and expanded the 'Swayam Prabha DTH Channel' (https://www.swayamprabha.gov.in) which provides many high-quality educational channels for online learning. Thus, educational technology or EdTech is the combined use of e-resources and educational practice to facilitate learning. During COVID -19 pandemic the medical institutes in India opted for online teaching for the undergraduate medical students, by means of various virtual platforms like Zoom, Google Meets, WebEx and other softwares. Online learning has definitely helped the MBBS students to continue learning amid this pandemic. However, limited data is available on the knowledge, attitude and practices towards e-learning by medical students from India during the pandemic. Though e-learning has been practiced by students for studying, its usefulness needs to be evaluated especially in developing countries. This study was planned to determine the knowledge, attitude and practices towards e-learning of first MBBS students during the COVID-19 pandemic. This is an initial study to document the perception of medical students towards e-learning from the hilly regions of India that will help to evaluate its acceptability among medical students.

\section{AIM AND OBJECTIVES}

This study was conducted with the aim of exploring the first MBBS student's knowledge, attitude, and practices towards e-learning. We took feedback from the students about e-learning regarding the difficulties they faced and the level of satisfaction. Thus, we wanted to evaluate the perception, effectiveness and usefulness of e-learning by first MBBS students during this pandemic.

\section{MATERIALS AND METHODS}

A questionnaire comprising twenty-five questions was developed by the authors, pertaining to various issues related to teaching learning activities during COVID-19 outbreak. The questionnaire was administered to the first MBBS students of government medical college, Himachal Pradesh after taking informed consent. The authors invited the students via e-mail and took consent to participate in the study during January to February 2021. Out of one hundred and twenty students, hundred volunteered to participate in the study. This study was conducted after getting clearance from the institutional ethics committee. The questionnaire had thematic sections on awareness about educational websites; online apps; engagement with e-learning; distractions; concerns regarding limitations; open-ended questions on personal preferences; general satisfaction; demographics etc. They were asked to tick an appropriate response. In a few questions even multiple answers were allowed. The students were assured that their responses will not alter the academic assessment and were encouraged to provide feedback with free mind. The data was compiled on an excel sheet and analysed to get the percentage for each question. We presented numerical data as frequencies and percentages. We explored associations of student's characteristics with responses using a chi-square test by SPSS software.

\section{RESULTS}

Forty-eight male and 52 female first MBBS students participated in the study. The response from these participants is summarised in Table 1 and Figure 1 and 2. All of these students have smartphones and about $10 \%$ of them have laptops too. All the students conveyed that they had sufficient information technology skills to participate in E-learning activities independently, and that they had an adequate internet connection for uninterrupted e-learning. As shown in the graph 1 of Figure 1, 41\% participants spent more than three hours surfing the internet every day. Sixty-six percent spent more time(>1 hour) on social sites like Facebook, WhatsApp, etc than e-learning. Moreover, $49 \%$ admitted that they did not actively attend the online learning classes. Eighty seven percent of students studied videos/animations of anatomy

\begin{tabular}{|c|c|c|c|}
\hline Sr No. & Aspect of e-learning evaluated & Yes(\%) & No(\%) \\
\hline 1 & $\begin{array}{l}\text { Awareness about academic } \\
\text { websites and educational material }\end{array}$ & 76 & 24 \\
\hline 2 & $\begin{array}{l}\text { Spending more time on social sites } \\
\text { than e-learning }\end{array}$ & 66 & 34 \\
\hline 3 & e-learning improves understanding & 70 & 30 \\
\hline 4 & Study videos or animations & 87 & 13 \\
\hline 5 & $\begin{array}{l}\text { Prepare notes of topics learnt } \\
\text { online }\end{array}$ & 61 & 39 \\
\hline 6 & Take tests after e-learning session & 30 & 70 \\
\hline 7 & $\begin{array}{l}\text { Feeling of insecurity about } \\
\text { e-learning by mediocre students }\end{array}$ & 40 & 60 \\
\hline 8 & $\begin{array}{l}\text { E-learning helps to write an answer } \\
\text { in exams }\end{array}$ & 56 & 44 \\
\hline 9 & $\begin{array}{l}\text { App based learning helps in better } \\
\text { understanding than self-learning }\end{array}$ & 40 & 60 \\
\hline 10 & $\begin{array}{l}\text { Easy to find relevant information } \\
\text { online }\end{array}$ & 70 & 30 \\
\hline 11 & $\begin{array}{l}\text { Require training program for } \\
\text { e-learning }\end{array}$ & 72 & 28 \\
\hline 12 & $\begin{array}{l}\text { Recommend conventional teaching } \\
\text { to be supplemented with e-learning }\end{array}$ & 65 & 35 \\
\hline
\end{tabular}

Asian Journal of Medical Sciences | Sep 2021 | Vol 12 | Issue 9 


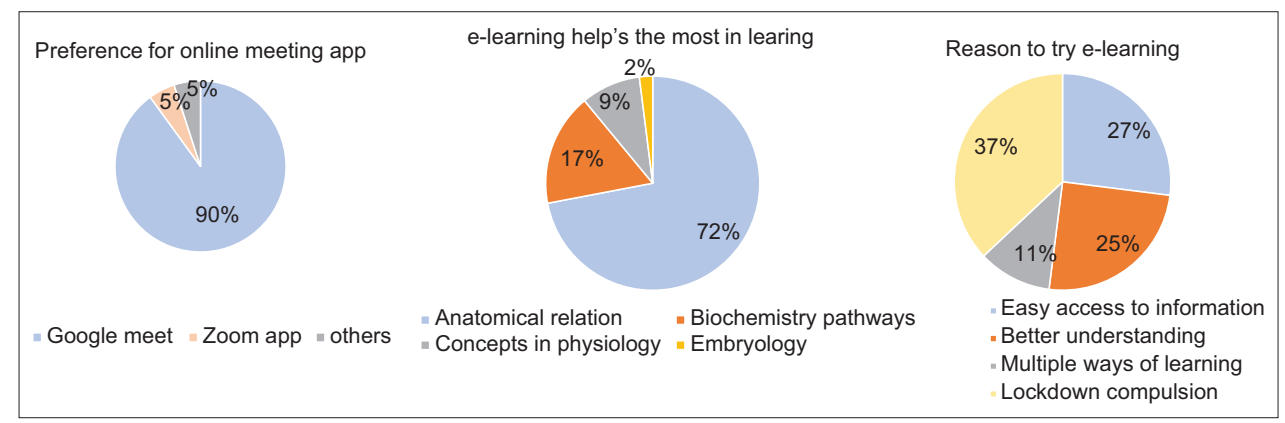

Figure 1: Perception about various aspects of e-learning

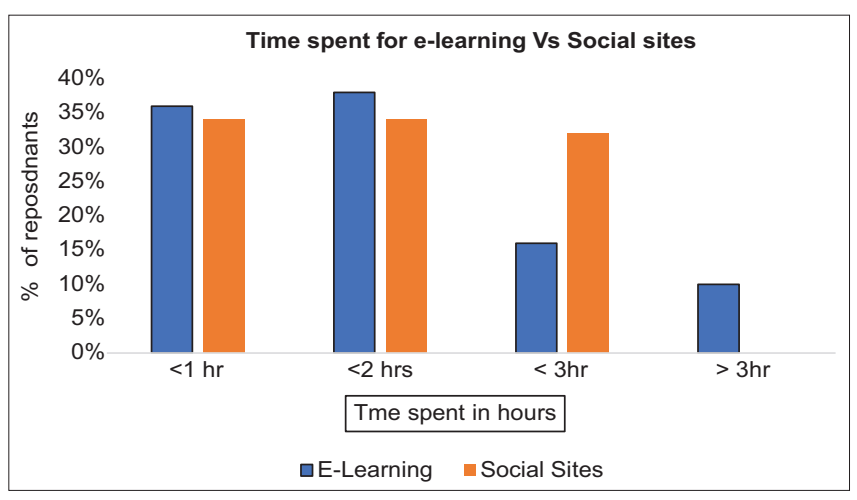

Figure 2: Time spent on internet for e-learning versus non-academic reasons

dissection, embryology or biochemistry/physiology/ pathways. However, $72 \%$, spent more time learning anatomy and claimed that E-learning helped the most in understanding anatomical relations. Majority of the students preferred to learn a new topic/concept from a teacher in a conventional way or by referring to a textbook but $21 \%$ preferred online browsing to learn a new topic/concept. Surfing the internet is preferred over referring to lecture notes or discussion with peers. But, the reasons to try e-learning were compulsions due to lockdown rather than better understanding, or ease of access. $40 \%$ of students responded that e-learning actually helps the most while preparing for routine study and another $40 \%$ of students conveyed that it helped them to write exams. $70 \%$ said that finding relevant information online is not difficult, and only $40 \%$ said app-based distance learning helps in better understanding than self-learning. There was unanimous opinion with the majority $85 \%$ suggesting that provision of free internet at institutes and provision of dedicated e-learning portals at institute will help to improve online learning process. The Chi-square analysis confirmed that the responses did not have any association with the gender ( $\mathrm{p}>0.05)$.

\section{DISCUSSION}

The COVID-19 pandemic has resulted in unprecedented health challenges leading to distuption of human life and activities. It has immensely impacted medical education as the primary focus of teaching institutes shifted from student education to management COVID-19 patients. This has impacted developing countries like India where medical education of government and private medical institutes varies significantly. At the time of admission in first MBBS, every student dream to treat patients and serve the society. They take efforts to excel in academics and be a good doctor. But the situation due to the COVID-19 pandemic was never expected. Medical teachers guide students to cruise through the tough medical curriculum. Nonetheless, this support system was shattered in these extraordinary times of novel coronavirus. Thus, the medical students are facing double trouble and finding it difficult to study the vast syllabus. Being new entrants to the field of medicine, first MBBS students seem to have suffered more and found it difficult to adjust to the new norms. ${ }^{2}$ The sudden change to online sessions from classroom teaching created significant pressure on medical undergraduate students. During these times the students were solely dependent on online study materials. However, there are many issues with online education and e-learning that need to be addressed. ${ }^{3-5}$ The pros and cons of e-learning and its effectiveness in undergraduate medical education in resource-limited countries like India need further evaluation. Hence, such studies are important to assess the first MBBS students' perception about e-learning and online classes. With the availability of smartphones and easy access to the internet, MBBS students were using e-learning modalities for studying medical subjects. E-learning has come to the rescue and was used optimally during this pandemic.

The findings of the present study were not unexpected. These are in line with the study done by Hiwarkar et al., ${ }^{6}$ which was done before the COVID-19 pandemic. They surveyed 236 students and found that e-learning helped in understanding various topics for $90.68 \%$ students and $84.32 \%$ recommended conventional teaching to be supplemented with e-learning. Alsoufi et al., ${ }^{7}$ conducted a cross-sectional survey on 3,348 medical students from Libya. $54.1 \%$ of students conveyed that, interactive 
discussions are achievable by means of e-learning. Only $38.2 \%$ agreed that e-learning can replace traditional teaching methods and medical schools can implement e-learning throughout the pandemic. Shete et al., ${ }^{8}$ in their study at Government Medical College from central India $(n=360)$ concluded that $61.7 \%$ students preferred a combination of face-to-face method and e-learning teaching as compared to e-learning alone. Buch et $\mathrm{al}^{9}$ in their study on $(n=905)$ students conveyed that, $69.10 \%$ students found tools like video conferencing, Google classroom, zoom meetings, etc. useful in flexibility and autonomy. $50.47 \%$ preferred combined methods of classroom teaching and e-learning. They concluded that the utility of e-learning has increased during the COVID-19 pandemic but students preferred e-learning in combination with traditional teaching. Suryawanshi et al., ${ }^{10}$ surveyed 286 students of the second year MBBS and pre-final year students where $48.2 \%$ students showed preference for blended mode of teaching. A total of $62.9 \%$ cited that there is lack of personal interaction with the teacher. They found significant differences between female and male students in a few issues which we did not find in our study. They also identified blended learning as an acceptable method of learning medical curriculum. Puljak et al., ${ }^{11}$ studied 2520 students of various health faculties in Croatia. Total of $39.6 \%$ found e-learning better and $24.9 \%$ found e-learning worse than traditional learning, rest were neutral in opinion. Of them, $55.1 \%$ indicated that they were afraid about lack of practical education. Bączek et al., ${ }^{12}$ conducted an online survey on Polish medical students $(\mathrm{n}=804)$. The respondents conveyed that the main advantages of online learning were the ability to attend from home (69\%), had continuous access to online materials $(69 \%)$ and learning at own pace $(64 \%)$ with the majority rating E-learning as enjoyable. Awadalla et al., ${ }^{13}$ studied responses from 358 medical undergraduate students in limited resource country, like Sudan and recommended that challenges of E-learning should be evaluated systematically and that effective strategies should be developed to overcome their inhibitory effects. Ibrahim et al., ${ }^{14}$ studied responses from 340 medical undergraduate students of Saudi Arabia. They concluded that medical students moderately accepted e-learning during the Covid-19 pandemic; however, training, designing suitable e-courses, more interaction, motivation, and blended learning were recommended. Vala et al., ${ }^{15}$ studied 250 first year MBBS students of Government Medical College, western India and concluded that $88 \%$ of students prefer traditional teaching methods rather than e-learning for practical classes. For better understanding and learning, medical students prefer that traditional classroom teaching should be followed by online video lectures that can be easily accessed by students at their convenient time. Adhikari et al., ${ }^{16}$ studied responses from 518 medical students from Nepal and recorded that, online classes are less effective over traditional lectures. They conveyed that the effectiveness of e-learning should be evaluated and the shortcomings of online learning should be addressed by the authorities. Syakurah et al., ${ }^{17}$ studied 3331 respondents from Indonesia and showed that most respondents had less satisfaction toward distance learning. They concluded that the institutions should continue evaluation so that the learning system remains effective and efficient. Dost et al., ${ }^{18}$ studied 2721 medical students across the UK and recorded that, students did not find online teaching to be engaging or enjoyable. Rana et al., ${ }^{19}$ conducted a study to assess the level of depression, anxiety and stress among first year MBBS students during this COVID-19 pandemic. They found about $58 \%$ participants had depression, $74 \%$ had anxiety and $32 \%$ had stress of various grades. Underlying one of the factors for these findings can be inability to attend classroom teaching and other academic activities. 0-learning can definitely help to rescue this stress and further studies are suggested. ${ }^{20,21}$

Across various countries as well as Indian states, the student responses for e-learning are similar, emphasizing the fact that it can complement but not replace traditional teaching. Didactic lecture is the simplest and convenient way to deliver subject information to a large group of medical students in one class. Students are accustomed with classroom teaching, practical and dissection work. Of course, there are many disadvantages associated with this teaching system. The most important one is that teachers find it difficult to actively engage the students. On the other hand, students find it difficult to keep interest in the given topic during the lecture hours as the students are passive participants. The student teacher ratio is usually poor, hence the interaction between them is limited. A mediocre student often finds it difficult to keep up with the pace of lecture proceedings. ${ }^{2-5}$ As a matter of course, the first MBBS students refer textbooks and classroom notes to study and prepare for assessments in first year MBBS. However, for better understanding of complex topics, e-learning is being used by the MBBS students. ${ }^{2}$ This has actually helped those students who were already using it.

The e-resources provides material that includes narration along with PowerPoint presentations, videos of practical classes and cadaver dissection, animation on biochemical/ physiological processes, simplified videos for complex topics like etiopathogenesis of disease, latest information on newer topics that has yet to find place in textbooks etc. The first MBBS students spend more time learning anatomy as e-learning helps the most in understanding anatomical relations. This is because of the fact that a 3 -dimensional view of the anatomic structure gives a long-lasting visual impression. Many of these e-learning 
resources are available as open educational resources that can be accessed free of cost. These are available at various educational websites like institute/university/faculty associations official web-pages, PubMed, WHO website, Wikipedia, You-tube etc. Medical students frequently visit these sites and use the information which can be considered as e-learning. ${ }^{1-5}$ However, searching the appropriate data online can be time consuming and difficult for the first MBBS students. Audio-visual aids help in keeping interest during online learning. Watching videos or animation helps students understand complex topics in less time. That is why watching dissection videos on YouTube has become popular among first MBBS students during periods of lockdown. ${ }^{3-6}$ Since gross anatomy is learnt through dissections of cadaver, the students were benefitted by online dissections videos freely available over the internet. Students find it more convenient and easier to search information online than to ask directly to the teachers. It is even faster than searching the same information in textbooks. Although there were no predominant opinions regarding lack of practical classes for biochemistry and physiology, the majority ( $90 \%$ ) of students expressed their concern that it will not be possible to compensate for the lack of cadaveric dissection during this time.

The e- learning mode provides multiple advantages. Here, a learner is free from the provision of resources like instructors, classroom and time constraints. Computers and e-resources also take care of individualized learning needs of the students. One can learn freely without being affected by others. ${ }^{11-13}$ The learner can work on his/her weaknesses by repeating the video or learning it through different websites or e-resources. Both slow and rapid learners are benefitted by adjusting the speed of presentation. These are a few limitations of traditional learning that can be resolved through e-learning. Nonetheless, e-learning does not come without limitations. It's liable to be underused and may fail to help students achieve learning objectives. E-learning requires motivation for learning and it is very difficult to maintain learner's interest over a larger span of time. ${ }^{14}$ During e-learning, students miss hands-on experience which they actually get in real laboratories and dissection halls. Inefficient handling of gadgets, e-resources and online content further adds to problems. Students may become casual towards e-learning with time. Hence, student's feedback on quality content and suggestions for improvement become crucial for achieving the goal of e-learning. ${ }^{15-18}$ The suggestions on "How to improve e-learning practices?" can be obtained from the students through feedback surveys. Quality teaching, provision of recorded lecture videos, PPT material for independent learning, availability of professors for query resolution, introduction of online exams etc are few of the suggestions. However, whether it's traditional teaching or e-learning, teachers need to be more engaging for better outcomes. ${ }^{7-10}$

Whether it's a traditional way or e-learning, students lose interest if they are unable to comprehend a topic. E-learning does compliment serious learners, but casual learners may find it difficult to get full benefits. Further, one can easily get distracted by social sites while using the internet. The time spent on the internet for e-learning was more than that for surfing social networking sites. The time spent on social networking sites must have been reduced as compared to pre pre-pandemic period as students have to use the internet for online classes and learning. Many students believe that the learning process has been hampered due to a lack of practical classes. Majority students agree about the continuation of online classes as they can complement traditional lectures. ${ }^{10-18}$

The role of teachers in the classroom remains unquestionable. Even though computers have become an integral part of the education process, it cannot replace teachers. The role of teachers is not to bombard students with information, but to help them gain knowledge. It is the teacher who helps students to develop wisdom. Teachers can assess students face to face and know their strengths and weaknesses, providing solutions to overcome them, simultaneously. They can adjust the pace of teaching and explain the topic in different words if required. This live experience of a facilitator interacting with the students is missing in the online platform where a student feels alien. Before this pandemic online learning has been less frequently practiced in developing countries like India due to lack of infrastructure, expertise, feasibility and awareness. ${ }^{20}$ Learning through practical, demonstrations and soft skill training is an integral part of medical education. However, organizing such practical sessions was not possible in current times of pandemic. Apart from this, students encountered multiple challenges, like, problems with content and perception of a topic along with technical issues like net connectivity during online educational sessions. Majority, do not like to take self-tests and during online examinations they tend to copy from books or internet. MCQs of varying grade of difficulty and time limitation for submission of answers can partially address this issue.

Though the majority of the students accepted that e-learning is effective, they recommend conventional teaching to be supplemented with e-learning. Undoubtedly, there are advantages that favour e-learning for the medical students; hence it seems to become an integral part of the future medical education. ${ }^{21}$ The disruption of medical education, caused by the COVID-19 pandemic, is likely to continue in the near future. Hence, assessment of knowledge, 
attitude and skills towards e-learning is crucial to plan appropriate training for e-learning in the undergraduate program. Encouraging medical students and faculty to collaborate to find and implement solutions seems to be the only way forward. More such studies are suggested for comparison of e-learning with conventional learning to gain insights about how to make it better. Nonetheless, it would be ideal to choose an integrated approach using both the methods i.e. traditional teaching supplemented with e-learning. This study will guide the authorities to improve the shortcoming of the online learning process for better outcome in future. Implementation of e-learning within the existing curriculum is challenging; however, it remains the only solution during COVID-19 imposed lockdown for continuation of academic activities.

In this study, the acceptance of e-learning among the first year MBBS students was not surprising as the students are resilient and adapted smoothly to the new ways of learning. The medical students are future doctors. The substandard training of doctors will pose a threat to future health care. Hence, we need to explore the pros and cons of e-learning and change medical teaching practices to supplement traditional teaching. In resource-limited countries like India, e-learning can play a crucial role in reaching masses especially during pandemics. Thus, e-learning is a powerful tool for teaching medical students and requires a wellthought-out strategy for successful implementation.

\section{LIMITATIONS OF THE STUDY}

The sample size of the present study was small, hence multicentric studies on a larger sample size are necessary to endorse the findings of this study.

\section{CONCLUSIONS}

The first MBBS students are using e-resources for learning various topics in anatomy, physiology and biochemistry. These resources have made a positive impact on various aspects of their learning especially in learning anatomy. We conclude that e-learning is a useful supplement to conventional classroom-based teaching in the first year of medical training. The e-learning methods need to be customized to actively engage and motivate the students and before incorporating it as a part of medical education in India, the shortcomings of virtual learning should be addressed by the authorities.

\section{REFERENCES}

1. Atreya A and Acharya J. Distant virtual medical education during COVID-19: Half a loaf of bread. Clin Teach. 2020;17(4):418-419. https://doi.org/10.1111/tct.13185

2. Hiwarkar M, Prasad A, Pant MK and Taywade O. Assessment of Negative Emotional States of Depression, Anxiety and Stress Among First MBBS students-A Cross Sectional Study. Walawalkar International Medical Journal. 2020; 7(1): 29-37.

3. Srivastava S, Jacob J, Charles AS, Daniel P, Mathew JK, Shanthi $P$, et al, Emergency remote learning in anatomy during the COVID-19 pandemic: A study evaluating academic factors contributing to anxiety among first year medical students, Medical Journal Armed Forces India.2020;77(Supplement 1): S90-S98.

https://doi.org/10.1016/j.mjafi.2020.12.012

4. Kapasia N, Paul P, Roy A, Saha J, Zaveri A, Mallick R, et al. Impact of lockdown on learning status of undergraduate and postgraduate students during COVID-19 pandemic in West Bengal, India. Child Youth Serv Rev. 2020; 116:105194.

https://doi.org/10.1016/j.childyouth.2020.105194

5. Gondhalekar AR and Gondhalekar MR. Medical education in the midst of a pandemic: What are the longer-term consequences for the doctors of tomorrow? Medical Journal Armed Forces India. 2021;77(Supplement 1): S4-S7.

https://doi.org/10.1016/j.mjafi.2020.11.030

6. Hiwarkar M and Taywade O. Assessment of knowledge, attitude and skills towards e-learning in first year medical students. Int J Res Med Sci. 2019; 7:4119.

https://doi.org/10.18203/2320-6012.ijrms20194977

7. Alsoufi A, Alsuyihili A, Msherghi A, Elhadi A, Atiyah H, Ashini A, et al. Impact of the COVID-19 pandemic on medical education: Medical students' knowledge, attitudes, and practices regarding electronic learning. PLoS One. 2020;15(11): e0242905. https://doi.org/10.1371/journal.pone.0242905

8. Shete A, Garkal K and Somwanshi N. Perceptions of MBBS Students Regarding E-learning during COVID-19 Lockdown, International Journal of Health Sciences and Research. 2020; 10(9): 319-322.

9. Buch AC, Rathod H and Kamble R. E-learning: The Scenario During COVID-19 Pandemic, J Med Edu. 2020; 19(2): e107227. https://doi.org/10.5812/jme.107227

10. Suryawanshi DM and Venugopal R. Preferences, perception and barriers to e-learning among medical students during COVID-19 pandemic lockdown in India. Int J Com Med Pub Health. 2020; 7:4100-4104.

https://doi.org/10.18203/2394-6040.ijcmph20204383

11. Puljak L, Čivljak M, Haramina A, Malisa S, Cavic D, Clinic D, et al. Attitudes and concerns of undergraduate university health sciences students in Croatia regarding complete switch to e-learning during COVID-19 pandemic: a survey. BMC Med Educ.2020; 20: 416.

https://doi.org/10.1186/s12909-020-02343-7

12. Bączek $M$, Zagańczyk-Bączek $M$, Szpringer $M$, Jaroszyński $A$ and Wożakowska-Kapłon B. Students' perception of online learning during the COVID-19 pandemic. Medicine. 2021; 100(7): e24821.

https://doi.org/10.1097/MD.0000000000024821

13. Awadalla MD, Mohmed MS, Ibrahim O, Elhassan $M$ and Mohammed M. Medical Students' Perception Towards E-learning During COVID 19 Pandemic in a high Burden Developing Country. 2020; 06 August 2020, PREPRINT (Version 1) available at Research Square. https://doi.org/10.21203/rs.3.rs-46982/v1

14. Ibrahim NK, Al Raddadi R, Al-Darmasi M, Al Ghamdi A, Gaddoury M, AIBar HM, et al. Medical students' acceptance and perceptions of e-learning during the Covid-19 closure time 
in King Abdulaziz University, Jeddah. J Infect Public Health. 2021;14(1):17-23

https://doi.org/10.1016/j.jiph.2020.11.007

15. Vala NH, Vachhani MV and Sorani AM. Study of evaluation of e-learning classes among medical students during COVID-19 pandemic phase in Jamnagar city. Natl J Physiol Pharm Pharmacol. 2020;10(12):1040-1042.

https://doi.org/10.5455/njppp.2020.10.07203202031072020

16. Adhikari P, Paudel S, Pandey RR, Parajuli A and Pyakuryal A. Effectiveness of E-learning during the covid-19 pandemic among the undergraduate medical students in Nepal: An online survey. Journal of Pharmacy Practice and Community Medicine.2020, 6(3):40-43.

https://doi.org/10.5530/jppcm.2020.3.13

17. Syakurah RA and Wiranto R. Evaluation of implementation and satisfaction of distance learning among medical students during COVID-19 pandemic in Indonesia, Int J Res Med Sci. 2020;8(12):4212-4218. DOI:

https://doi.org/10.18203/2320-6012.ijrms20205291

18. Dost S, Hossain A, Shehab M, Shehab M, Abdelwahed A and
Al-Nusair L. Perceptions of medical students towards online teaching during the COVID-19 pandemic: a national crosssectional survey of 2721 UK medical students. BMJ Open. 2020;10: e042378.

https://doi.org/10.1136/bmjopen-2020-042378

19. Rana S, Taywade O, Sharma V and Hiwarkar M. Study of depression, anxiety and stress among first year Medical students in Government Medical College, Himachal Pradesh during COVID-19 pandemic, Asian Journal of Medical Sciences. 2021;12(6): 90-94.

https://doi.org/10.3126/ajms.v12i6.36687

20. Gupta S, Dabas A, Swarnim S and Mishra D. Medical education during COVID-19 associated lockdown: Faculty and students' perspective, Medical Journal Armed Forces India. 2021; 77(Supplement 1): S79-S84.

https://doi.org/10.1016/j.mjafi.2020.12.008

21. Bolatov AK, Seisembekov TZ, Askarova AZ, Baikanova RK, Smailova DS and Fabbro E. Online-Learning due to COVID-19 Improved Mental Health Among Medical Students. Med Sci Educ. 2020;1-10.

https://doi.org/10.1007/s40670-020-01165-y

Author's Contribution:

MH, SR, BM- Contribution to conception and design; SR, MH- Designing the study, Acquisition, analysis and interpretation of data; OT- Statistical analysis; OT,

BM- Drafting manuscript, revising manuscript critically for important intellectual content; $\mathrm{MH}$ - Accountable for all aspects of the research work and publication. All authors have approved of the version of manuscript to be published.

Work attributed to:

Shri Lal Bahadur Shastri Government Medical College and Hospital, Ner Chowk, Mandi, Himachal Pradesh, India.

Orcid ID:

Dr. Onjal Taywade- (1) https://orcid.org/0000-0002-3373-0363

Dr. Monali Hiwarkar- (D) https://orcid.org/0000-0001-9141-8856

Source of Funding: None, Conflict of interest: None. 